\title{
UNA POSICIÓN DE DENTRO, PERO FUERA: LAS ARTISTAS Y SUS OBRAS EN EL CAMPO DEL ARTE
}

\author{
Lourdes Méndez Pérez \\ Universidad del País Vasco UPV/EHU \\ lourdes.mendez@ehu.eus
}

\section{RESUMEN}

La ideología sociosexual y la ideología carismática en el campo del arte sitúan a las artistas en una posición conflictiva de estar dentro, pero fuera, del campo del arte. Están dentro de él en el quehacer artístico como productoras de obras expuestas y vendidas a través de diferentes circuitos, pero su reconocimiento profesional en muchas ocasiones no se produce. Esta problemática se analiza en el campo del arte del Estado espańol de las Autonomías.

Palabras Clave: ideología sociosexual, arte, reconocimiento artístico, Estado español de las Autonomías.

\section{A POSITION FROM WITHIN, BUT OUTSIDE: THE ARTISTS AND THEIR WORKS IN THE FIELD OF ART}

\section{Abstract}

The sociosexual ideology and the charismatic ideology in the field of art place artists in a conflictive position of being inside, but outside the field of art. They are in it in the artistic work as producers of works exhibited and sold through different circuits, but their professional recognition is often not recognized. This problem is analyzed in the field of art of the Spanish State of Autonomies.

KeYwORds: sociosexual ideology, art, artistic recognition, Spanish State of Autonomies.

DOI: http://doi.org/10.25145/j.atlantid.2018.09.002 
La ideología sociosexual dominante sobre lo que significa ser mujer o ser hombre desde la que se interpretan como derivados de una naturaleza hipotéticamente femenina o masculina los roles y funciones que cada sexo debe asumir, unida a la permanencia en el campo del arte de una ideología carismática (Bourdieu, 1977) que niega la incidencia del sexo, entendido como categoría social, en la obtención de reconocimiento artístico, sitúan a las artistas en una conflictiva posición de estar dentro, pero fuera, del campo del arte. Están dentro de él en el quehacer artístico y como productoras de obras expuestas y vendidas a través de diferentes circuitos, pero, llegado el momento de alcanzar un grado significativo de reconocimiento avalado por su trayectoria profesional, en su mayoría desaparecen. A pesar de que un significativo número de especialistas suele negarlo, la valoración experta de artistas y obras, fundamental para obtener legitimidad en un campo tan competitivo y mistificado como el del arte, pasa por el tamiz de un orden sociosexual de larga duración que, en toda sociedad, instaura la «valencia» diferencial de los sexos y su jerarquía (Héritier, 1996). Olvidar los efectos ideales y materiales de ese tamiz conduciría a descuidar analíticamente el hecho de que el campo del arte está estructurado en base a las variables de sexo, raza/etnicidad y clase a través de las cuales se organizan desigualdades y jerarquías que afectan al sujeto artista como a la percepción estética y evaluación crítica de sus obras. Tanto en el caso de las producidas por artistas «étnicos» como en las realizadas por artistas mujeres, todo lleva a pensar que, o bien la sensibilidad estética de los especialistas en arte no está lo suficientemente desarrollada, o bien no es lo bastante "pura» como para abstraerse de la carga de prejuicios que rodean a esas obras y a quienes las producen.

Mi objetivo en estas páginas es profundizar en la problemática enunciada contextualizándola en el campo del arte del Estado español de las Autonomías. Para lograrlo he seleccionado diversas fuentes documentales que me permiten elaborar un análisis reteniendo una temporalidad de más veinticinco años. En 1991 Emakunde/ Instituto Vasco de la Mujer encargó elaborar un informe sobre la posición de las mujeres en la producción artística de la Comunidad Autónoma Vasca. Es el contenido de dicho Informe el que analizaré en primer lugar reflexionando al mismo tiempo sobre una herramienta, el «Kunstkompass», utilizada desde 1970 para establecer el palmarés de los cien artistas más reconocidos internacionalmente. Acto seguido me adentraré en los cuatro círculos de reconocimiento jerarquizados teorizados por Bowness (1989) y cuyo funcionamiento, todavía hoy, puede observarse en el campo del arte. A continuación, para ilustrar la posición de estar dentro pero fuera del campo del arte que ocupan las artistas, analizaré dos artículos publicados en 2008 en el suplemento Babelia del periódico El País en los que un crítico y una crítica de arte dan cuenta de dos exposiciones de artistas mujeres celebradas en el Estado español. A modo de epílogo abierto, para mostrar que en 2018 las artistas siguen estando dentro pero fuera del campo del arte, y que esa posición se refleja en la asignación de premios y en la programación expositiva de las instituciones públicas de arte, me detendré en una investigación con base estadística (Quémin, 2013) y en datos referidos al Estado español de las Autonomías recabados por dos asociaciones: Mujeres en las Artes Visuales (MAV) y Plataforma A. 
El análisis del Informe 8 de Emakunde sobre Las mujeres en la producción artística de Euskadi reviste un doble interés porque proporciona datos cuantitativos, y porque recurre a especialistas en arte para que los interpreten. Los datos remiten al año 1991 y se centran en la adjudicación de premios a artistas mujeres, en especial el Gure Artea, en la participación de las artistas en galerías del País Vasco, en el acceso de éstas al mundo laboral y en su participación en la Feria Internacional de Arte Contemporáneo (ARCO) en el año 1991. El Informe también tiene en cuenta que el número de alumnas matriculadas en la Facultad de Bellas Artes de la Universidad del País Vasco y que finalizan sus estudios es sensiblemente superior al de alumnos. Las cifras recogidas muestran que las artistas están infrarrepresentadas en todos los ámbitos que les permitirían consolidarse dentro del contexto del arte contemporáneo. El Informe recoge que un 30\% de artistas mujeres expusieron en galerías de la CAV en 1991, frente a un 70\% de artistas varones, y que en ARCO 91 la presencia de obras de artistas mujeres rondaba el 5\%, sin que se apreciaran diferencias significativas entre los datos referidos al Estado español y los relativos a Alemania, Italia, Francia, Gran Bretańa o Estados Unidos. Las cifras son claras: la desigual presencia en contextos significativos del arte contemporáneo de artistas mujeres y de artistas varones es un hecho empíricamente verificable. Un hecho que, si se tiene en cuenta que para que una obra obtenga la etiqueta de contemporánea no basta con que haya sido creada por un artista vivo puesto que se trata de «una etiqueta internacional que constituye una de las mayores apuestas, constantemente reevaluada, de la competitividad artística» (Moulin, 1992: 45), puede interpretarse como consecuencia material de la desigual valoración de las obras producidas por artistas varones y artistas mujeres por parte de los especialistas en arte. Hay que insistir aquí en que para que una obra obtenga la etiqueta de contemporánea su productor o productora debe formar parte de los circuitos artísticos internacionales dándose a conocer a través de galerías, exposiciones, museos y salas de ventas; y consiguiendo que galeristas, marchantes, comisarios, coleccionistas y críticos se ocupen de su promoción, valoración y adquisición. Serán precisamente un crítico e historiador del arte y una galerista, ambos del País Vasco, los encargados de interpretar los datos del Informe 8 que dan cuenta de la desigualdad entre artistas varones y artistas mujeres en el campo del arte del País Vasco.

El crítico de arte, reflexionando sobre por qué el número de artistas mujeres que exponen en galerías del País Vasco es menor que el de artistas hombres, insiste en un hecho históricamente cierto: «La incorporación de la mujer al trabajo del arte ha sido posterior a la del hombre», para extraer de él una curiosa conclusión: «En la actualidad conviven múltiples generaciones y promociones de artistas, con lo cual hay más artistas hombres que mujeres» (Informe 8, 1994: 158). Al parecer, para él, la situación inicial de inferioridad numérica de las artistas en el campo del arte sigue siendo un hecho, una especie de hándicap histórico que marca el presente. El crítico no toma en consideración el dato de que se licencian en Bellas Artes más alumnas que alumnos, dato estadístico que debería reflejarse en esa convivencia de múltiples generaciones y promociones de artistas saldándose con una mayor presencia de artistas 
mujeres. Pero sigamos. Pasando sin transición del ámbito de las cifras al mercantil, y del mercantil al de los roles de sexo, en una sucesión de relaciones causa-efecto fascinantes, el crítico afirma que "como los que compran son hombres, compran a hombres [...] aunque también se compra la proyección del artista como potencial ganancia económica. En este aspecto, parece que el hombre va a continuar mejor su obra y trayectoria, mientras que la mujer tiene sus tareas, los hijos [...] Existe esa razón de tipo económico y psicológico» (Informe 8, 1994: 158). Situándose en similar línea interpretativa la galerista dice, al ser interrogada sobre la participación de las artistas en los circuitos comerciales, que «el sexo no tiene nada que ver, que lo que importa es la obra [ya que] lo único que interesa a la gente es la obra. Lo que puede ocurrir es que haya más mujeres que abandonen. El mundo del arte es muy duro de por sí, no por ser hombre ni mujer. Hay más hombres, en todo lo que sobresale, que mujeres» (Informe 8, 1994: 167). Y, volviendo al crítico, hablando de ARCO afirma que ese tema es «muy distinto, porque ahí influyen otros intereses, se admite una galería en función de intereses económicos, y ésta lleva artistas en función de ello. No es lo mismo, no hay representación, ni hay un jurado ni nada, sino que es el dinero" (Informe 8, 1994: 167). Si bien es cierto que los intereses comerciales guían eventos como ARCO y que no hay jurado que seleccione a los o las artistas, no lo es menos que cada galería trabaja con ciertos artistas y no con otros. Dicho de otro modo, toda galería dispone de un conjunto de artistas y obras que pretende promocionar y si decide llevar a ARCO la obra de uno de sus artistas, y no la de una de sus artistas, esa decisión obedece a los criterios del o la galerista, criterios que, si se atiende a lo que dice el crítico de arte, parecen estar tan mediatizados por el mercado como los utilizados por ARCO a la hora de decidir qué galerías tendrán un stand en la Feria y cuáles no.

En resumen, lo que los dos especialistas en arte que interpretaron los datos del Informe 8 dijeron es que: 1) los artistas son más numerosos que las artistas, 2) que son los hombres los que compran obras y, por lo tanto, compran obra de hombres, 3) que no importa el sexo, sino la obra, y 4) que las mujeres tienen sus tareas y sus hijos y que esto puede afectar a su trayectoria profesional. Y lo que no dijeron es por qué, si lo que importa es la obra y no el sexo de quien la produce, los hombres compran mayoritariamente obras de hombres, ni por qué el hecho de ser mujer puede incidir en la trayectoria profesional de las artistas, mientras que el hecho de ser hombre también parece incidir, pero a la inversa, puesto que «hay más hombres que mujeres en todo lo que sobresale». Y como es lo que no dijeron lo que interesa, para hacerlo emerger hay que recordar el funcionamiento de un campo del arte definido por Bourdieu como un sistema de relaciones objetivas entre esos agentes (artistas, galeristas, críticos, marchantes, comisarios de exposiciones, teóricos del arte...) o esas instituciones (por ejemplo, museos, gustos estéticos legítimos), y lugar de luchas por el monopolio del poder de consagración, donde se engendran constantemente el valor de las obras y la creencia en ese valor (Bourdieu, 1977: 7). Es la ideología carismática, piedra angular de dicho campo, la que juega el rol de difusora de la creencia, colectivamente compartida, de que ni el artista ni sus obras le deben nada a nadie y que si sólo unos pocos de cada generación son reconocidos como grandes artistas, y sus obras como auténticas obras de arte, eso se debe a que 
desinteresados "herederos culturales», poseedores de un exquisito gusto estético y de un "capital cultural», han sabido descubrirlos. Es ese credo, periódicamente renovado, el que impide que surjan preguntas sobre los condicionantes sociales, sexuales, económicos, políticos y simbólicos que intervienen en el campo del arte. Y es también ese credo el que oculta dos hechos empíricamente verificables: el de que «las artes son jerárquicas y funcionan mediante la autoridad de ciertos predecesores que dan la regla, [mientras que] los imitadores siguen simplemente esa autoridad» (Schwimmer, 1995: 16), y el de que nuestras sociedades siguen confiando «el rol de 'dar la regla' al sexo masculino en todas las actividades» (1995: 17). Si se retienen estas ideas se comprenderá mejor lo que a continuación sigue.

El «Kunstkompass» es una herramienta que, desde 1970, se utiliza como indicador del valor de la reputación de la que gozan los artistas. Su objetivo es establecer, año tras año, el listado de los cien artistas más reconocidos y, para lograrlo, quienes utilizan esta herramienta creada en Alemania por un periodista recurren a una especie de jurado informal compuesto por críticos de arte, directores de museos y grandes coleccionistas privados. Son los juicios de esos especialistas, unidos a los datos extraídos de las reseñas sobre tal o cual artista publicadas en las grandes revistas internacionales de arte, a la participación de los y las artistas en grandes eventos expositivos con proyección internacional como la Documenta de Kassel o la Bienal de Venecia y al hecho de que expongan individualmente en grandes museos o centros de arte, los que se utilizan para establecer el palmarés de artistas. En el año 2001 ningún artista del Estado español formaba parte de dicho palmarés, copado por artistas de Estados Unidos y de Alemania (Quemin, 2002) y, en cuanto a las artistas, su presencia no superaba el 10\%. Si en 2001 el «Kunstkompass» barajaba a 10000 artistas para establecer su clasificación, en 2007 disponía de una base de datos que concernía a más de 150 000, lo que, como indica uno de sus responsables, impide que los profesionales del arte puedan tener una visión de conjunto de las carreras de todos ellos, visión que, según él, «una máquina sí puede» tener. Y es esa máquina concienzudamente alimentada la que, en 2007, mantenía el mismo porcentaje que en el 2001 de artistas mujeres entre los cien primeros puestos del ranking. De esas realidades puede deducirse, sin demasiado esfuerzo, que quienes en la práctica controlan el campo del arte son varones occidentales de nacionalidad estadounidense, alemana o británica. Por eso habría que plantear la hipótesis de que son ellos quienes siguen reproduciendo el marco conceptual que hace difícil legitimar a las artistas, a los artistas étnicos y, por extensión, a sus obras.

\section{EL CAMPO DEL ARTE Y LOS CUATRO CÍRCULOS DE RECONOCIMIENTO}

En el campo del arte funcionan cuatro círculos de reconocimiento claramente jerarquizados (Bowness, 1989) que, aunque no actúan simultáneamente, se retroalimentan. Cuatro círculos que no escapan a los valores de sexo/género dominantes en cada sociedad y período histórico, ni a la etnicidad o a la posición de clase del sujeto artista. El primero de ellos, compuesto por los y las artistas, es el más restringido. 
$\mathrm{Al}$ igual que en los otros tres, en él se emiten juicios sobre las obras que no remiten en exclusiva, aunque así se afirme, a cuestiones puramente intraestéticas o artísticas. Ese círculo es de gran importancia para los y las artistas puesto que es en él, en el que sus pares les reconocen como coleccionistas que, en contacto con los artistas, llevan a cabo transacciones económicas que conciernen a sus obras. El segundo está constituido por diferentes expertos en arte -críticos, comisarios de exposiciones, conservadores de museos-, a menudo vinculados a instituciones públicas y que se encuentran temporal y espacialmente distanciados de los y las artistas. El tercer círculo lo componen los marchantes y coleccionistas que, una vez establecida la reputación de un/a artista, empiezan a interesarse por sus obras. Y el cuarto círculo lo forma el heterogéneo público receptor que a través de galerías, exposiciones, museos, accede a las obras y, a veces, a los y las artistas que las han producido. Pero el público receptor no es una instancia legitimadora, puesto que la legitimación ya se ha llevado a cabo en los tres primeros círculos. Lo que se le propone al público es aquello que ya ha sido reconocido como obra de arte por diferentes especialistas. El modelo de análisis de Bowness presta mucha atención a cómo se articula espacial y temporalmente la construcción de las reputaciones artísticas en la modernidad, una articulación especialmente importante para las artistas occidentales y también para los otrora "primitivos» y hoy transmutados en «étnicos» (Méndez, 2009).

En el campo del arte del siglo xx, si algo caracteriza a los y las artistas que forman parte del primer círculo de reconocimiento es que pretenden distanciarse de las definiciones del arte dominantes. Al hacerlo, crean obras que no pueden emerger como tales (ni ellos o ellas como artistas) si se les aplican los criterios de percepción y apreciación vigentes (Michaud, 1999). El reconocimiento artístico de esas obras y artistas exige, como en su día exigió el arte de las primeras vanguardias, la superación de dichos criterios y su sustitución por otros. Mientras que esto sucede, el efecto práctico de la permanencia de los anteriores criterios de percepción y de apreciación sería el inicial rechazo de esas obras y artistas por parte de ese público heterogéneo que, de todos modos, carece de legitimidad para emitir juicios estéticos o artísticos normativos. El rechazo inicial hacia las nuevas obras y artistas sería por lo tanto «una eventualidad [...] que forma parte de la obra misma [...] [puesto que] el trabajo del artista reposa sobre la trasgresión de las fronteras cognitivas que definen lo que puede ser percibido o no como arte» (Heinich, 1998: 78). Por su parte, críticos, comisarios, marchantes y coleccionistas ocupan el rol inverso al de los y las artistas y «su tarea consiste en integrar en el campo del arte lo que ha sido concebido para transgredir fronteras, ampliando las fronteras del ámbito artístico a objetos o actos que tradicionalmente no eran relevantes» (Heinich, 1998: 79). Una tarea de integración que, en lo que respecta a las artistas y a sus obras, todavía parece resultarles problemática.

Si a lo hasta ahora expuesto se le añade la tan difundida concepción ultraliberal del éxito individual y algunos de los lugares comunes desarrollados por el discurso posmoderno, el panorama de condicionantes sociales y simbólicos que se perfila y al que deben enfrentarse las artistas es arduo. Arduo porque el impacto de esos lugares comunes sobre el arte contemporáneo ha contribuido a la emergencia en él de una temática políticamente correcta, la de la diferencia sexual, que hay que 
examinar teniendo en cuenta las interacciones entre la actual redefinición del arte, la identidad del/la artista y de la obra, y la posibilidad de que éstas últimas (aun siendo explicadas) comuniquen algo a un público que a menudo desconoce las claves del arte contemporáneo y que no renuncia a la certeza identitaria de sexo/género. En este sentido, el problema es tanto artístico como político, puesto que lo que se debate en el arte contemporáneo «no es tanto una definición consensuada de lo bello y del talento artístico, como una definición consensuada del arte y de la identidad de artista» (Heinich, 1998: 74). Uno de los lugares comunes más poderosos del enfoque posmoderno es la idea según la cual el individuo de hoy en día se desplaza constante y furtivamente en el escenario de la vida pública para manifestarse en sus múltiples y no siempre claras realidades y manifestar al mismo tiempo lo que considera lo más propio, lo último, el ethos, el eidos y el pathos frente al estructurante y compulsivo logos (Azcona, 1996: 40). Este lugar común que concierne a la forma de entender al individuo se articula con otros como los de la diferencia sexual, la inautenticidad, la hibridación, el mestizaje, muy exitosos en el arte contemporáneo. Probablemente, y en lo que atañe a la identidad de los sujetos, sea el antropólogo usamericano Clifford el que con más claridad ha expresado esos lugares comunes. Para él hay que concebir «la identidad colectiva como un proceso inventivo discontinuo, a menudo híbrido [...]. Al intervenir en un mundo interconectado, uno es siempre en diversos grados 'inauténtico': atrapado entre culturas, implicado en otras" (Clifford, 1995 [1988]: 25-26). Si se aplica esto a obras visuales y a artistas la idea central consistiría en defender que obras y artistas, provengan de donde provengan, son productos (y sujetos) híbridos. Pero la noción de hibridación oculta la especificidad de determinadas culturas, obras y artistas, y deja intactos los implícitos del orden sexual, orden simbólico de larga duración, que instaura la «valencia» diferencial de los sexos y su jerarquía. Según la antropóloga Héritier (1996), ninguna sociedad es ajena a esa «valencia» diferencial de los sexos que, en cada una, estructura el mundo social y simbólico, jerarquiza lo masculino y lo femenino y atribuye a lo masculino un valor superior al que otorga a lo femenino. Es la jerarquía de esa "valencia» diferencial de los sexos la que habría que transformar si se quiere que la condición sexuada del sujeto artista sea irrelevante para quienes ostentan el poder de crear al creador, el de consagrar sus obras, el de establecer cuál es el gusto estético legítimo y el de producir los saberes autorizados sobre el arte. Por eso es necesario saber cómo ese orden simbólico sexual condiciona la atribución a los artistas y a sus obras de una legitimidad cultural y simbólica que sigue negándosele a las artistas y a las suyas. Y también es necesario saber cómo ese orden afecta a un sistema de consagración que no se ha construido al margen de él, sino en base a él.

Dada la situación expuesta, cabe plantear algunas cuestiones sobre las que las investigaciones feministas sobre el campo del arte deberían indagar sin perder de vista las intersecciones entre los contextos locales y globales en los que se producen, y por los que circulan, las obras de las artistas actuales. Si, tal y como sostengo, la creación plástica y visual añade algo a la posición que ocupan las artistas y sus obras en el arte contemporáneo, y ese algo es residual, hay que seguir investigando sobre por qué los especialistas en arte siguen mayoritariamente valorando las obras de las artistas desde el prisma de una diferencia sexual que sólo parece afectarles a ellas. 
Asimismo, si «los circuitos dominantes, principales y secundarios, de museos, galerías y publicaciones (los que podríamos denominar 'universalizadores') construyen la 'escena artística internacional'» (Mosquera, 2001: 23), y si, como ya se ha enunciado, los países anglosajones, en especial Estados Unidos, juegan un papel clave en el mercado, «en la formulación de las opciones artísticas y, en particular, en la consagración de artistas de primer plano» (Quemin, 2002: 9), habría que aclarar cómo incide ese contexto global sobre el grado de reconocimiento alcanzado por las artistas.

\section{DOS ARTÍCULOS, DOS EXPOSICIONES}

Cuando la edición de ARCO 08 se encontraba en su ecuador, el periódico $E l$ Pais (16 de febrero de 2008) publicó en Babelia, página contra página, dos artículos que, a mi entender, merecen ser comentados con un cierto detalle. El primero de ellos, firmado por Ángela Molina, se centraba en la exposición La mirada iracun$d a$, comisariada por Xabier Arakistain y Maura Reilly. El segundo, firmado por el historiador y crítico de arte Francisco Calvo Serraller, versaba sobre otra exposición, Amazonas del arte nuevo, comisariada por Josep Casamartina y Pablo Jiménez. Empezaré por éste último.

Comentando la valía de esa exposición que reúne 116 obras de 41 artistas mujeres que participaron en los sucesivos ismos del siglo xx, Calvo Serraller, escamoteando del rol político y social del movimiento feminista, atribuye a la Primera Guerra Mundial un papel decisivo en la «liberación femenina». Fue esa guerra la que, según él, que sólo entrecomilla «liberación» y no «femenina», permitió a las mujeres comprobar «de manera fehaciente su capacidad para hacer, disfrutar y padecer todo». Escamoteadas así las luchas y reivindicaciones feministas de la época, y tras enumerar una larga lista de las artistas seleccionadas para la exposición, escribe: «No creo que sea una mala carta de presentación para una exposición que se nos presenta en términos de reivindicación de "género" el que, gracias a un buen trabajo de exploración, amplíe nuestro siempre escaso bagaje de conocimientos; pero [...] la aportación de la misma es mucho más ambiciosa y feraz, porque la selección de obras es, sin ambages, estupenda, con lo que al final del recorrido, el visitante, no voy a decir que obvie, pero sí logra olvidarse del "género"». Si se lee este párrafo con atención dos cosas deberían interpelarnos: la sutileza con la que este crítico de arte que, semana tras semana, publica sus textos en El País, minimiza que los comisarios de la exposición la plantearan en términos de «reivindicación de 'género'» para subrayar su «buen trabajo de exploración», y cómo, hecho esto, concluye que gracias a ese buen trabajo que se plasma en la selección de obras, se olvida el "género» de sus autoras sin obviarlo. Hablando claro, lo que se nos está diciendo, una vez más, es que lo que cuenta es la calidad de las obras y no el sexo de quienes las producen. Y a lo que una vez más no se está respondiendo es: 1) a por qué la excelencia de esas artistas y obras no se ha reconocido hasta ahora, 2) a por qué se obvia el sexo, sin olvidarlo -se supone que se obvia por la excelencia de las obras-, y 3) a por qué ha habido que esperar hasta 2008 para que ese «buen trabajo de exploración» haya sido posible. Al igual que muchos de sus pares, el historiador y crítico de arte Calvo 
Serraller no parece saber que hace más de tres décadas que las historiadoras y críticas de arte feminista empezaron a recuperar la historia de las artistas y a organizar exposiciones como, por ejemplo, la que bajo el título L'Autre moitié de l'avant-garde reunió en 1982 a algunas de esas artistas que ahora Calvo Serraller parece descubrir.

Firmado por Ángela Molina, el segundo artículo tiene un título: «Las mamás de Blancanieves», y un subtítulo: "La exposición La mirada iracunda, en Vitoria, indaga en las falsas respuestas que da el feminismo al arte». Es cierto que en las facultades de ciencias de la información suelen insistir en lo importante que es acuñar un titular llamativo que retenga la atención de quienes leen la prensa. En este caso el objetivo está de sobra logrado y, para que nadie se pierda, anticipa algunas pistas sobre el contenido del artículo atribuyendo sujetos reales al mencionado título y al subtítulo: «las mamás» son las feministas, Blancanieves son las artistas, y la manzana envenenada las «falsas respuestas que da el feminismo al arte». Quizás otras atribuciones sean posibles, es lo bueno -y también lo malo- de títulos y subtítulos tan metafóricos. El modelo de la historia del arte, escribe la autora del artículo desde una posición pretendidamente crítica, «es abrumadoramente masculino por necesidad. Describe la evolución de las formas como una guerra crucial de padres e hijos y define el proceso creativo desde el punto de vista metafórico de un encuentro sensual (cuando no sexual) entre el pintor y su musa, [...] y así parece seguir hoy, cuando la creación llamada "de mujeres" ha acabado convirtiéndose en un fetiche de las multinacionales museísticas». Molina, en vez de explicar por qué el modelo de la historia del arte es masculino por necesidad, por qué perdura y por qué la «creación llamada 'de mujeres' se ha convertido en un fetiche para las multinacionales museísticas", prosigue su artículo aludiendo a algunas exposiciones de artistas mujeres celebradas en 2007 que, según ella, sirvieron para «ilustrar la desposesión y degradación histórica del principio femenino y analizar una cultura cuyas definiciones de la autoridad creativa son encubiertamente patriarcales». Tras estos prolegómenos en los que mezcla un poco de todo aterriza en la exposición $\mathrm{La}$ mirada iracunda, cuyo "gran mérito descansa en su (sana) capacidad de "ofensa" al espectador, dado el contexto en el que se exhibe, una ciudad, Vitoria, profundamente conservadora. [...] [y] demuestra indirectamente que el feminismo, como ha ocurrido con otros movimientos sociales, ha sido desplazado por las nuevas políticas sociales del presente».

Lo que Molina nos está diciendo es que como es el feminismo el que ha orientado La mirada iracunda, y como éste es cosa del pasado, sólo los espectadores de la conservadora Vitoria, al parecer ignorantes de esas «nuevas políticas sociales del presente» (¡a qué nuevas políticas sociales se estará refiriendo, quizás a las políticas neoliberales que son el pan nuestro de cada día?), pueden sentirse «ofendidos» por las obras expuestas. Y se llega así a su valoración de éstas últimas. Como se ha visto, al contrario que Calvo Serraller, Molina no escamotea el feminismo -tampoco hubiera podido hacerlo dada la exposición sobre la que escribe-, simplemente decide que es cosa del pasado y que lo que ahora tenemos es una mitología del feminismo que «nace en el momento que se queda atrás [...] [esto] debería servir para exigir a la obra una dignidad estética que se aliara con su propia capacidad para superar unos condicionantes históricos». ¿Dignidad estética de la obra? ¿Capacidad de la obra para 
superar condicionantes históricos? Estamos de lleno en una perspectiva filosófica, la de la estética formalista, tras la que se agazapa la sacrosanta idea de autonomía de la obra de arte. Tras un sucinto recorrido por las obras de algunas artistas, concluye Molina que «inalterablemente femeninas, estas artistas de "mirada iracunda" bailan para salirse del espejo de la autoridad masculina, pero no lo suficiente para superar la ansiedad por jugar en el mismo marco de representación. Puestas a jugar dentro de él, ellas han de desfilar por la misma ventanilla. Y si no, regurgitar la manzana envenenada, levantarse del ataúd de cristal y bailar otra danza. Una danza de autoridad».

Quien recuerde el cuento de Blancanieves sabe que no es su mamá, sino su madrastra, obsesionada por su apariencia física y su belleza, la que interroga al espejo y le pregunta, machaconamente, «espejito, espejito, quién es la más bella...». Hasta que el espejito nombra a Blancanieves. Un nombramiento que desemboca en el consabido drama. Al parecer para Molina es el feminismo igualitario el que ha puesto a las artistas ante el espejo de la autoridad masculina, y no la autoridad masculina la que se les ha impuesto a las mujeres en todos y cada uno de los campos de actividad social, incluido el artístico, como filtro evaluador de sus prácticas. Y peor aún, ya que las artistas han aceptado el juego que las sometan a las mismas reglas. ¿Acaso no están ya sometidas a las mismas reglas, les guste o no, las compartan o no? Y ¿son esas reglas las mismas para ambos sexos? Dados los criterios de valor y de juicio estético que numerosos especialistas siguen aplicando a las artistas y a sus obras, todo parece indicar que no lo son. ¿O lo que quiere decir la autora del artículo es que las obras de algunas artistas de "mirada iracunda» no alcanzan el nivel de «excelencia» requerido - ¿por quién?- para obtener un grado significativo de reconocimiento en el campo del arte contemporáneo? Por último, regurgitar la manzana envenenada, si no interpretamos mal, consistiría en rechazar la mitología del feminismo igualitario afirmándose como «inalterablemente femeninas», para, desde esa feminidad inalterable, bailar la danza de la autoridad. ¿Se referirá Molina a la danza de la diferencia?, ¿a alcanzar autoridad en el arte afirmando la diferencia de lo femenino? Por si de eso se tratara, recordemos que en 1979 la socióloga feminista materialista francesa Colette Guillaumin se preguntaba por qué en determinados momentos "ciertos grupos oprimidos [...] reivindican la "diferencia"» (Guillaumin, 1992 [1979]: 89), y sostenía que en la palabra "diferencia» se habían colado "todos nuestros rasgos 'específicos' [...] uniéndose a las ideologías folkloristas clásicas que, de la negritud a la feminidad, siempre han pretendido que los dominados tienen -ellos- algo particular y que todo, en ellos, es particular. (Los otros, los dominantes, contentándose sin duda con ser generales)» (Guillaumin, 1992: 91). Además, afirmar la diferencia, reivindicar que, como mujeres, se poseen caracteres propios, conlleva pensar "como si los grupos de los hombres y de las mujeres pudieran existir en sí, y presentar una permanencia que les permitiera definirse fuera de la relación. Se trata de una forma imaginaria de afirmar la independencia del grupo dominado" (1992: 93). En efecto, la diferencia ya se nos ha adjudicado a las mujeres, al igual que se nos ha atribuido un inalterable "femenino" $y$, en el campo del arte, esa adjudicación no había desembocado, en 2008, en un reconocimiento de las artistas -ni de los artistas «étnicos»- como dadores de la regla al arte. 


\section{EPÍLOGO: LA PERSISTENCIA DEL DENTRO, PERO FUERA}

Y no habían desembocado en ese reconocimiento en 2008, ni tampoco en 2013, tal y como demuestran las estadísticas elaboradas por el sociólogo del arte Alain Quémin (2013) tras analizar varios palmarés utilizados para construir el grado de reputación de cada artista. Tan llamativo es el fracaso de las artistas que el sociólogo, que en anteriores investigaciones no había retenido el sexo como variable sociológica, esta vez se ve obligado a hacerlo y a dedicar un capítulo completo de su libro al tema. Afirma Quémin que «el mundo del arte contemporáneo está muy generizado y que [...] las mujeres ocupan globalmente una posición dominada. Esto es cierto para las artistas y su reconocimiento institucional, y lo es todavía más para el mercado, y la tendencia se encuentra también en lo que concierne al poder en el mundo del arte contemporáneo" (Quémin, 2013: 383). Y, concluye el sociólogo, «es como si, estructurándose, el mundo del arte contemporáneo hubiese logrado mantener a las mujeres cada vez más a distancia [...] éstas parecen enfrentarse a un 'techo de cristal' que parece prohibir toda perspectiva de acceder a la paridad entre los artistas más visibles» (2013: 385). Esta desoladora constatación, unida a la ya manida metáfora del «techo de cristal» que detiene las trayectorias de las artistas, lleva a preguntarse si, en 2018, puede verificarse lo mismo en un Estado español que en 2007 se dotó de una Ley de Igualdad cuyo artículo 26 contempla acciones positivas en los ámbitos del arte y la cultura. No es casualidad si, tras la aprobación de dicha Ley, se fundara en mayo de 2009 la asociación Mujeres en las Artes Visuales (MAV) que, entre otras actividades, recaba datos sobre la posición de las artistas mujeres en lo que denominan el sistema del arte. Cualquiera que consulte sus informes, accesibles online, constata que en la edición de ARCO 18, la presencia de artistas mujeres españolas alcanzó un desolador $6 \%$, y que el 71,4\% de los premios fueron asignados a hombres. Esos datos, además de confirmar los análisis de Quémin, condujeron por vez primera a algunas artistas españolas a organizar una acción para visibilizar su presencia en la citada Feria. Si, de esta feria de arte, desplazamos la mirada hacia lo que acontece en centros y museos de arte de titularidad pública el panorama es igualmente desolador. En la Comunidad Autónoma Vasca los datos recogidos por Plataforma A, asociación creada en 2011, demuestran la infrarrepresentación de las artistas (Arrázola, 2016) en lo referido a exposiciones individuales en sus tres grandes instituciones de arte. Así, entre 2002 y 2013, el Museo de Bellas Artes de Bilbao programó 44 exposiciones individuales, todas de artistas hombres. Lo mismo sucedió entre 2003 y 2013 con un Guggenheim-Bilbao que dedicó el $100 \%$ de sus exposiciones individuales a artistas hombres. Tal y como señala Arrázola, la situación es muy similar en museos y centros de arte ubicados en otras comunidades autónomas. Porque el problema es estructural y remite a la discriminación por razón de sexo, y al androcentrismo inherente a las categorías acríticamente utilizadas por quienes programan los eventos, no es de extrañar que también en el Museo Nacional Centro de Arte Reina Sofía, buque insignia del arte contemporáneo del Estado español, se constate la misma infrarrepresentación de las artistas y de sus obras. 
A la luz de lo expuesto a lo largo de estas páginas, espero haber mostrado que es imprescindible no perder de vista, en los análisis antropológicos feministas del campo del arte, la posición de dentro pero fuera que en él ocupan las artistas, y también comprender lo que acontece en sus diferentes circuitos, circuitos en los que no sólo prevalecen, sino que también se reproducen, las desigualdades de sexo, clase y raza/etnicidad. Y en esa reproducción, a un tiempo material y simbólica, las principales instituciones públicas de arte -léase museos- juegan un papel central. Y, pregunta impertinente, para acabar este epílogo: ¿por qué no se aplican, ni en el Estado español ni en la Comunidad Autónoma Vasca, los artículos sobre arte y cultura de la Ley de Igualdad en las instituciones públicas de arte?

Recibido: 27-5-2018; aceptado: 21-6-18 


\section{BIBLIOGRAFÍA}

Arrazola, Tx. (2016). "Plataforma A, colectivo vasco para la incorporación normalizada de las mujeres en el sistema del arte». Kultur, vol. 3, núm. 5, pp. 291-318.

Azcona, J. (1996). Teoría y práctica en antropología social. Bilbao: UPV/EHU.

Bourdieu, P. (1977). «La production de la croyance: contribution à une économie des biens symboliques». Actes de la Recherche en Sciences Sociales, núm. 13, pp. 13-45.

Bowness, A. (1989). The Conditions of Success. How the Modern Artist rises to Fame. Londres: Thames \& Hudson.

Clifford, J. (1995). Dilemas de la cultura. Barcelona: Gedisa.

Guillaumin, C. (1992). Sexe, race et pratique du pouvoir. L'idée de nature. Paris: Côté-femmes.

Heinich, N. (1996). Etre artiste. Les transformations du statut des peintres et des sculpteurs. Paris: Klincksieck.

Heinich, N. (1998). «Des conflits autour de l'art contemporain». Le Débat, núm. 98, pp. 72-86.

Héritier, F. (1996). Masculino/Femenino. El pensamiento de la diferencia. Barcelona: Ariel.

Méndez, L. (2009). Antropología del campo artístico. Del arte primitivo [...] al contemporáneo. Madrid: Síntesis.

Michaud, Y. (1999). Critères esthétiques et jugement de goût. Nîmes: J. Chambon.

Mosquera, G. (2001). «Algunas notas sobre globalización y curadoría internacional». Revista de Occidente, núm. 238, pp. 17-30.

Moulin, R. (1992). L’Artiste, l'institution et le marché. Paris: Flammarion.

Quémin, A. (2002). L'art contemporain international: entre les institutions et le marché. (Le rapport disparu). Paris: J. Chambon/Artprice.

Quémin, A. (2013). Les stars de l'art contemporain. Notoriété et consécration artistiques dans les arts visuels. Paris: éditions du CNRS.

Schw immer, E. (1995). «El signo y su lectura», en L. Méndez, Antropología de la producción artística. Madrid: Síntesis. 
